\title{
Correlations Among New Dental and Cranial Measurements
}

Massimo Scioletti ${ }^{1}$, Dino Scioletti ${ }^{1}$, Andrea Ferrara ${ }^{1}$, Salvatore Dettori ${ }^{2}$, Dario Stefani ${ }^{3}$, Roberto Carboni ${ }^{2}$, Rosalba Floris ${ }^{4}$, Ruggero D'Anastasio ${ }^{5,6}$, Joan Viciano ${ }^{5^{*}}$

${ }^{1}$ Dental clinic "San Francesco", via Mons. Tesauri, 10, 66034 Lanciano, Italy.

2 Dental clinic "Dettori", via Donizetti, 13, 07037, Sorso, Italy.

3 Dental clinic "Stefani", viale Colombo, 87, 09045, Quartu Sant'Elena, Italy.

${ }^{4}$ Department of Life Sciences and Environment, State University of Cagliari, Cittadella Universitaria S.S. 554 - km 4,500 09042 Monserrato (CA)

${ }^{5}$ University Museum, 'G. d'Annunzio' University of Chieti-Pescara, Piazza Trento e Trieste, 1, 66100 Chieti, Italy.

${ }^{6}$ Department of Medicine and Aging Science, 'G. d'Annunzio' University of Chieti-Pescara, Via dei Vestini 66013 Chieti Scalo, Italy

Keywords: physical anthropology, anthropometry, principal component analysis

ABSTRACT Cranial and dental anthropometry is commonly used in many areas of research, e.g., in forensic anthropology and paleoanthropology. We propose new craniometric and dental landmarks and distances that may have important applications in physical anthropology. Furthermore, a classical anthropometrical approach was applied to quantify the correlation between dental and cranial measurements, which were taken on 30 Middle Ages adult crania from Sardinia (Italy).

Principal components analysis was performed to explore the correlations among inter-landmark distances. The first component showed correlations between the cranial base and maxillary inter-landmark distances (the 'cranial base' system). The second component exclusively demonstrated correlations among maxillary and dental inter-landmark distances (the 'oral cavity' system). The third component showed positive correlations between the zygomatic and midline maxillary inter-landmark distances, and high negative loadings that include the bilateral styloid process and midline maxillary landmarks (the 'upper cranium' system).

The inter-landmark dental distances correlate with inter-landmark cranial distances that have not been described previously. These data can be applied in other research and clinical areas.

In the past, anthropologists generally studied the human skull from a purely descriptive point of view, and only in relatively recent times have they began to study skulls through comparisons of skull morphologies. This applies not only to the class of Primates, but for the whole series of Vertebrates, to highlight specific and different morphological characteristics in relation to the biological species or sub-species, or to the sex and age, or other such characteristics. The first attempts were made by Louis-Jean-Marie Daubenton (1716-1799), Johann Friedrich Blumenbach (1752-1840), Petrus Camper (1722-1789) and James Cowles Prichard (17861848). Their comparative anatomical studies were resumed and continued in France by Étienne Geoffroy Saint-Hilaire (1772-1844), Georges Cuvier (1769-1832), and other researchers, who gave them a very special impulse, so that it can be said that they established a new science: cranial anthropom- etry. Some years before, Anders Retzius (17961860) was the first to use the cephalic index in physical anthropology to classify ancient human remains from Europe. Soon after, Paul Pierre Broca (1824-1880) developed new anthropometric methods and coined a technical terminology that had hitherto been unknown (Spencer, 1997).

In 1906, the Convention of Monaco established international standards for cephalometric and craniometric data collection, which were listed in the Lehrbuch der Anthropologie (Martin and Saller, 19571966). In 1908, Aldobrandino Mòchi (1875-1931), and later Raffaello Parenti (1907-1977) (Parenti, 1955), observed that certain cranial forms, such as

*Correspondence to:

Dr. Joan Viciano, University Museum, 'G. d'Annunzio' University of Chieti-Pescara, Piazza Trento e Trieste 1, 66100 Chieti, Italy, e-mail: joanviciano@gmail.com 
those listed by Giuseppe Sergi (1841-1936) and Paolo Mantegazza (1831-1910), corresponded to particular values of the cephalic index of Retzius (Capasso, 2015). Then during the twentieth century, several anthropometric indices were proposed and applied to describe the ranges of variability of morphometrical cranial features, to classify skulls into categories, and to evaluate the distribution patterns within modern and ancient human populations (e.g., Perez et al., 2007; Hanihara et al., 2003; Relethford, 2002; Ngeow and Aljunid, 2009).

The contributions of classical cranial anthropometry to the study of the evolutionary scenarios of hominin cranial shapes and sizes have been well demonstrated, and in archaeological and forensic anthropology, measures and indices are still commonly used to reconstruct a biological profile of an individual (e.g., Kimbel and Rak, 2010; Gapert et al, 2013; Veroni et al., 2010; Gonzalez, 2012). At the same time, metrics are usually employed in dental anthropology for sex determination (Viciano et al., 2015) and estimation of age (Irurita et al., 2014).

The aim of this article is to propose new craniometric and dental landmarks and inter-landmark distances. The landmarks represent anatomical, muscular, vascular and neuronal structures that are involved in physiological and biomechanical functions, and they delimit anthropometric linear measurements, which we have experienced to be particularly useful in clinical practice. The clinical data available to us strongly suggest that the proposed measurements are extremely useful for treating cases of malocclusion and incorrect posture of the skeleton. We treat malocclusion clinical cases by acting on the distances between the proposed anthropometric landmarks, bringing them back to values in healthy individuals (Moyers et al., 1996). Our clinical results suggest the existence of a correlation between the proposed dental and craniometric measurements.

The new dental and craniometric landmarks and measurements may have important applications in other fields of research of physical anthropology because they (i) supplement the landmarks and the anthropometric distances previously published, (ii) suggest new correlations between dental and cranial measurements and, more generally, (iii) may contribute to better clarify relations between the various anatomical regions of the skull.

For these reasons a classical anthropometrical approach was applied to quantify the correlation between the new dental and cranial measurements.

\section{MATERIALS AND METHODS}

Materials

The skeletal remains used in the present study were dated to the Middle Ages and were part of a large wellpreserved ossuary that was discovered during the restoration works on the San Lucifero Church in Sardinia (Italy). It is believed that these skeletal remains are those of the monks and the people of a small community that lived in the vicinity of the church. Due to the provenance of these remains, some of their anthropological data are limited (e.g., sex, age estimation) (Sarigu et al., 2016).

A total sample of 30 adult crania without mandibles and of individuals of unidentified sex was analyzed in the present study. These specimens were selected from the osteological collection housed in the Sardo Museum of Anthropology and Ethnography, at the University of Cagliari (Sardinia, Italy). The vaults of these crania were open, and a series of hinges provided access to the endocranial structures and allowed direct collection of the cranial and dental measurements. Only well-preserved specimens were used in the present study (i.e., without pathological signs or taphonomic alterations). Thanks to their excellent state of preservation, it was possible to localize the deepest landmarks accurately, otherwise difficult to detect by X-ray or other imaging studies.

\section{Data acquisition and analysis}

A MicroScribe portable digitizer (Model MX, Immersion Corporation, San Jose, CA, USA) and the integrated MicroScribe Utility Software were used to collect the data for the distances between the anatomical landmarks with an accuracy of $0.05 \mathrm{~mm}$, considered for the midline and both sides of the skull (Table 1, Figure 1). The spatial position of the landmarks and the related measurements were collected with the skull oriented according to the Frankfurt horizontal plane. Many standard craniometric landmarks were included, with the remaining landmarks chosen to represent the overall size of the maxilla. In addition, with the bilateral dental landmarks, a number of constructed landmarks were calculated that were established as the midpoints of the distances between these bilateral dental landmarks. As a merely descriptive classification, the landmarks were divided into three anatomical regions: (i) the oral cavity, which included the $p r$, sta, $D 4, D 5, D 6, D 7, p t 4, p t 5, p t 6$ and $p t 7$ landmarks; (ii) the base of the cranium, which included the $p h t, b a, o, g f b$, stl and bms landmarks; and (iii) the upper cranium, which included $n, s t b, z m$ and op landmarks (see Table 1 and Figure 1). Subsequently, a series of virtual triangles were constructed that had at least the central vertex on a landmark of the maxilla. The inter-landmark distances were calculated from the raw data of the landmarks of these virtual triangles on the left or right side, depending on the availability. As it is assumed that an ideal skull is symmetrical, if both sides were available, the mean was calculated to adjust values, to avoid the use of more sophisticated techniques for the analysis of asymmetry (Figure 2).

The statistical analysis was performed using the IBM® SPSS ${ }^{\circledR}$ Statistics 22.0 software. A descriptive analysis was performed to calculate the minimum, maximum, mean and standard deviation for each inter-landmark distance. This analysis characterized the study sample and allowed detection of any major errors in the database collection or the data processing. Principal component analysis (PCA) 


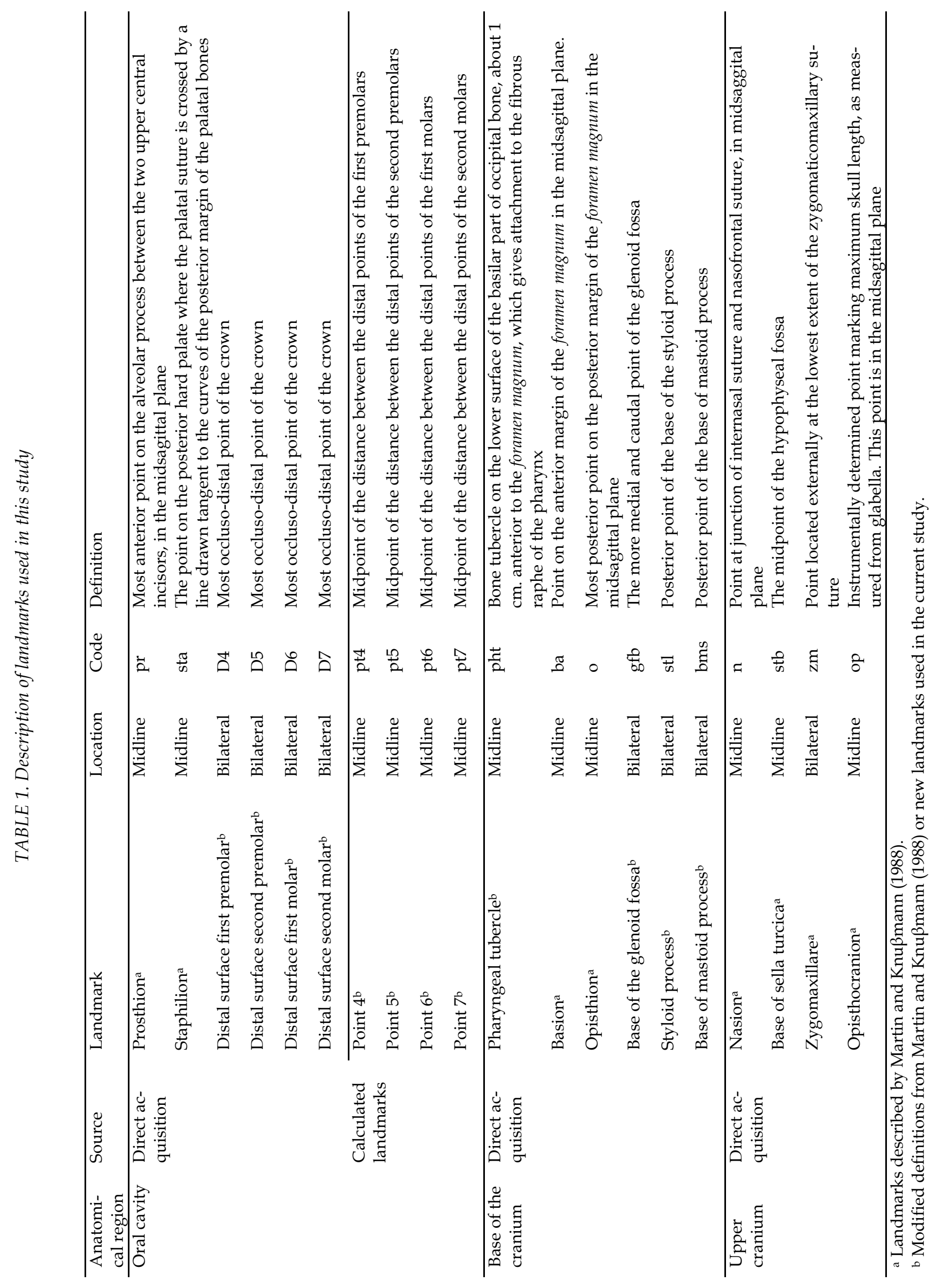




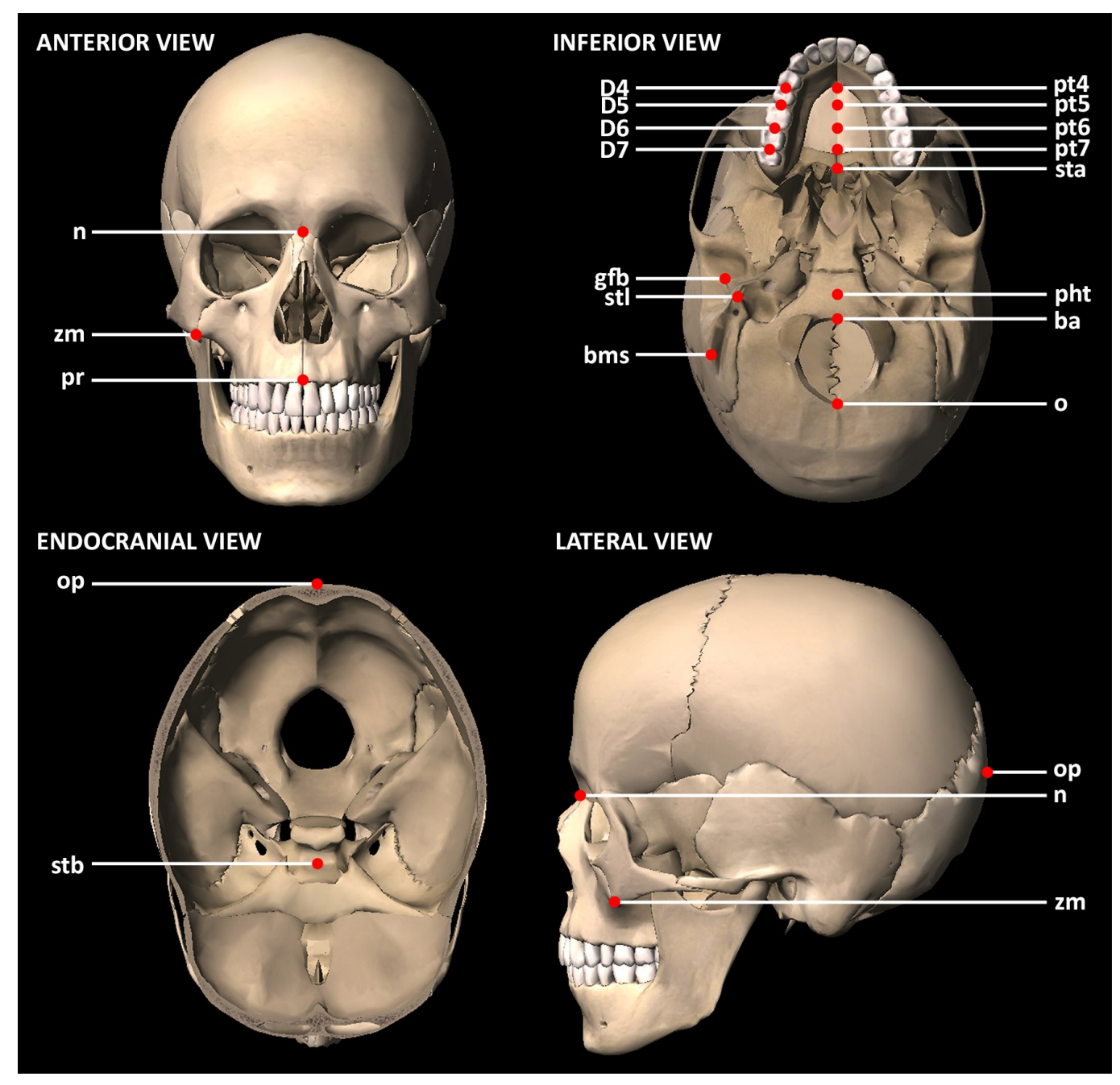

Figure 1. Anatomical landmarks used for measurements recorded

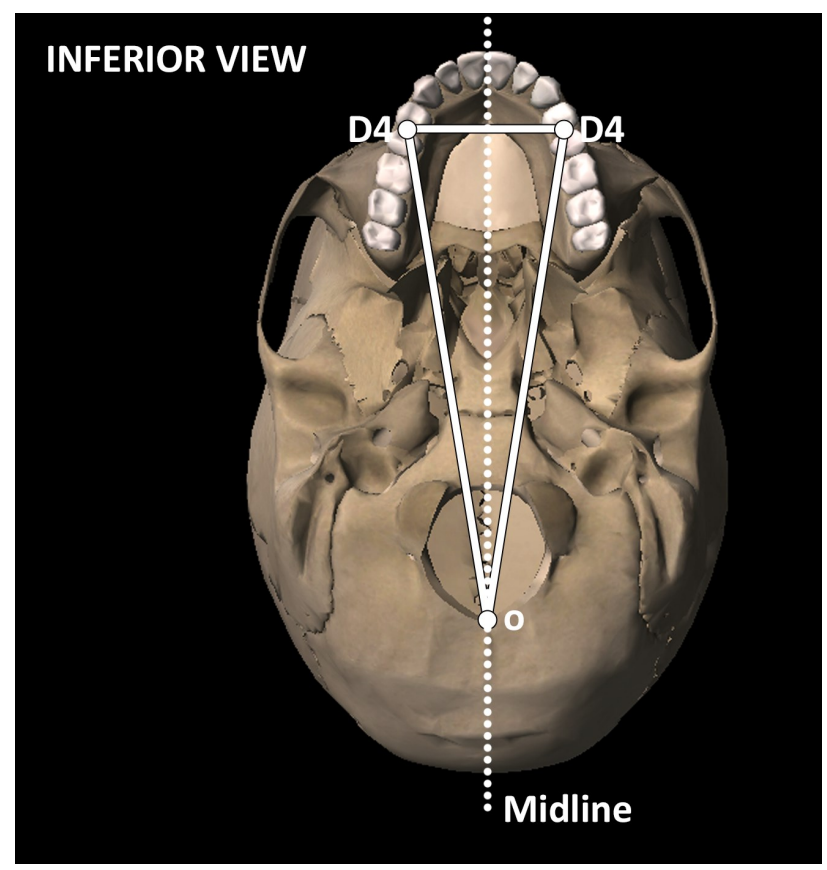

Figure 2. Example of one virtual triangle constructed in this study: triangle $D 4-o-D 4$ (all 62 virtual triangles are specified in Table 2). Three inter-landmarks distances were calculated from the raw data: $D 4-o$ (to the right side from the midline), $D 4-o$ (to the left side from the midline), and $D 4-$ $D 4$. Then, the mean was calculated to adjust the values for the bilateral inter-landmark distances D4-o 
was carried out to explore the relative relationships and particular features among these inter-landmarks distances. Data were first assessed for normality using the Kolmogorov-Smirnov one-sample test. Next, a PCA was performed, generating a small number of principal components that can be used to explain most, if not all, of the variation of a sample. Orthogonal varimax rotation of these components with eigenvalues greater than 1.0 was used to simplify the component structure. The relationships between the different inter-landmark distances were then investigated through Pearson product-moment correlations. Significance was set to $p<0.05$.

\section{RESULTS}

The sample consisted of 30 skulls, with 28 landmarks identified and collected ( 24 anatomical, four calculated) (see Table 1). A total of 62 virtual triangles were also obtained, with at least the central vertex located on the midline of the skull or maxilla (Table 2). Table 2 shows the descriptive analysis of the inter-landmark distances. The results of Kolmogorov-Smirnov test indicated that all of the inter-landmark distances were normally distributed.

Principal component analysis returned ten components that explained $94.6 \%$ of the variation. Here, only the first three components were considered to facilitate the interpretation of the data, and these explained $67.1 \%$ of the var- iation in the data set (Table 3). The loadings of the original variables on these three rotated principal components are illustrated in Figure 3.

Component one (PC1) accounts for $42.9 \%$ of the sample variance and demonstrates positive loadings for all inter-

TABLE 3. Ten components of the principal components analysis of the interlandmark distances

\begin{tabular}{lccc}
\hline $\begin{array}{c}\text { Principal } \\
\text { component }\end{array}$ & Eigenvalue & $\begin{array}{c}\text { Explained } \\
\text { variance (\%) }\end{array}$ & $\begin{array}{c}\text { Cumulative } \\
\text { variance (\%) }\end{array}$ \\
\hline PC1 & 30.052 & 42.932 & 42.932 \\
PC2 & 9.137 & 13.052 & 55.985 \\
PC3 & 7.792 & 11.131 & 67.116 \\
PC4 & 5.432 & 7.759 & 74.875 \\
PC5 & 3.723 & 5.319 & 80.194 \\
PC6 & 3.346 & 4.779 & 84.973 \\
PC7 & 2.233 & 3.190 & 88.163 \\
PC8 & 1.993 & 2.847 & 91.010 \\
PC9 & 1.370 & 1.957 & 92.967 \\
PC10 & 1.159 & 1.655 & 94.623 \\
\hline
\end{tabular}
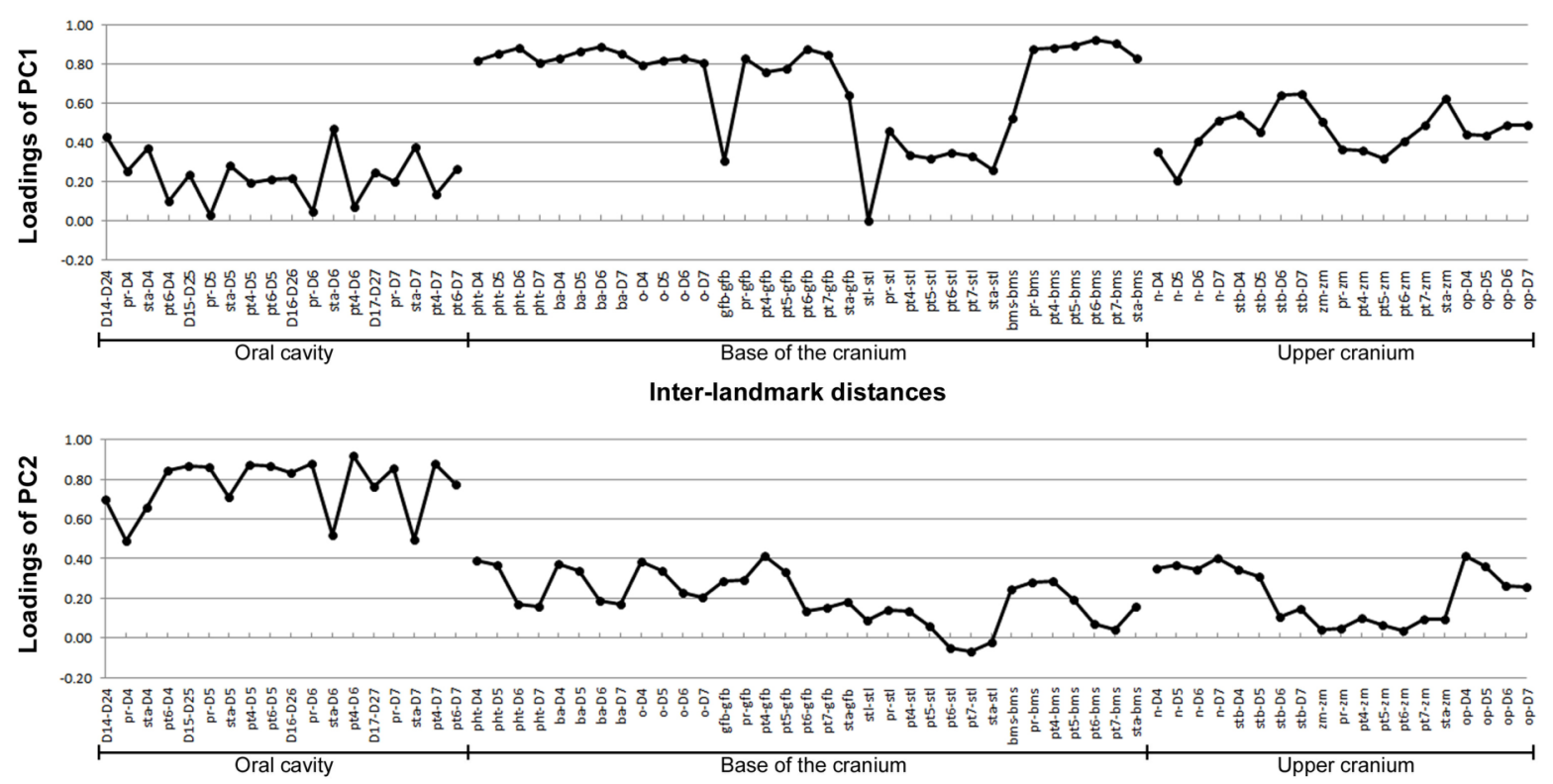

Inter-landmark distances

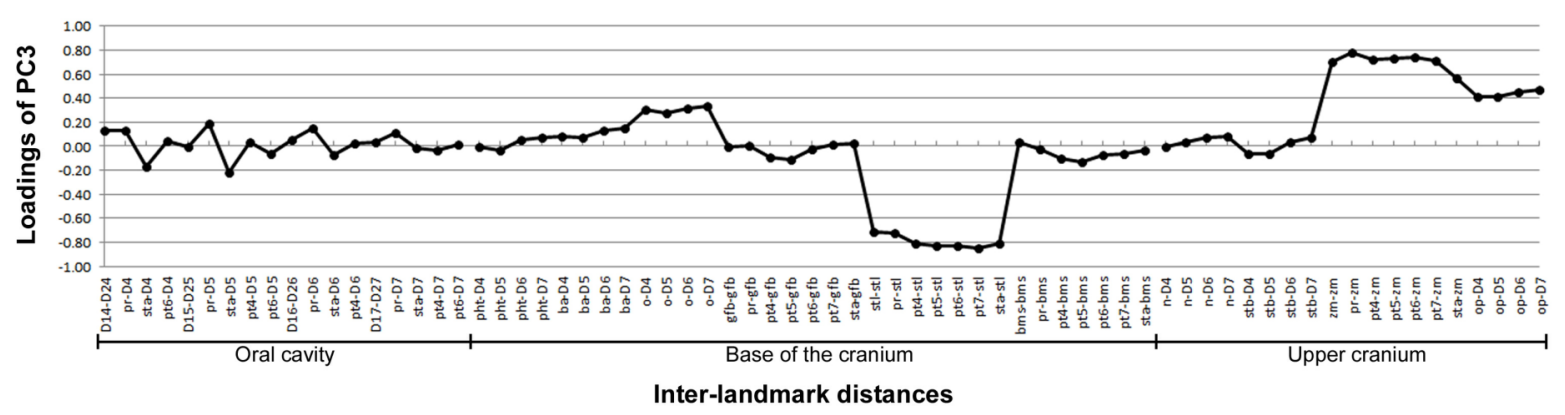

Figure 3. The loadings of the original variables on the three rotated principal components 


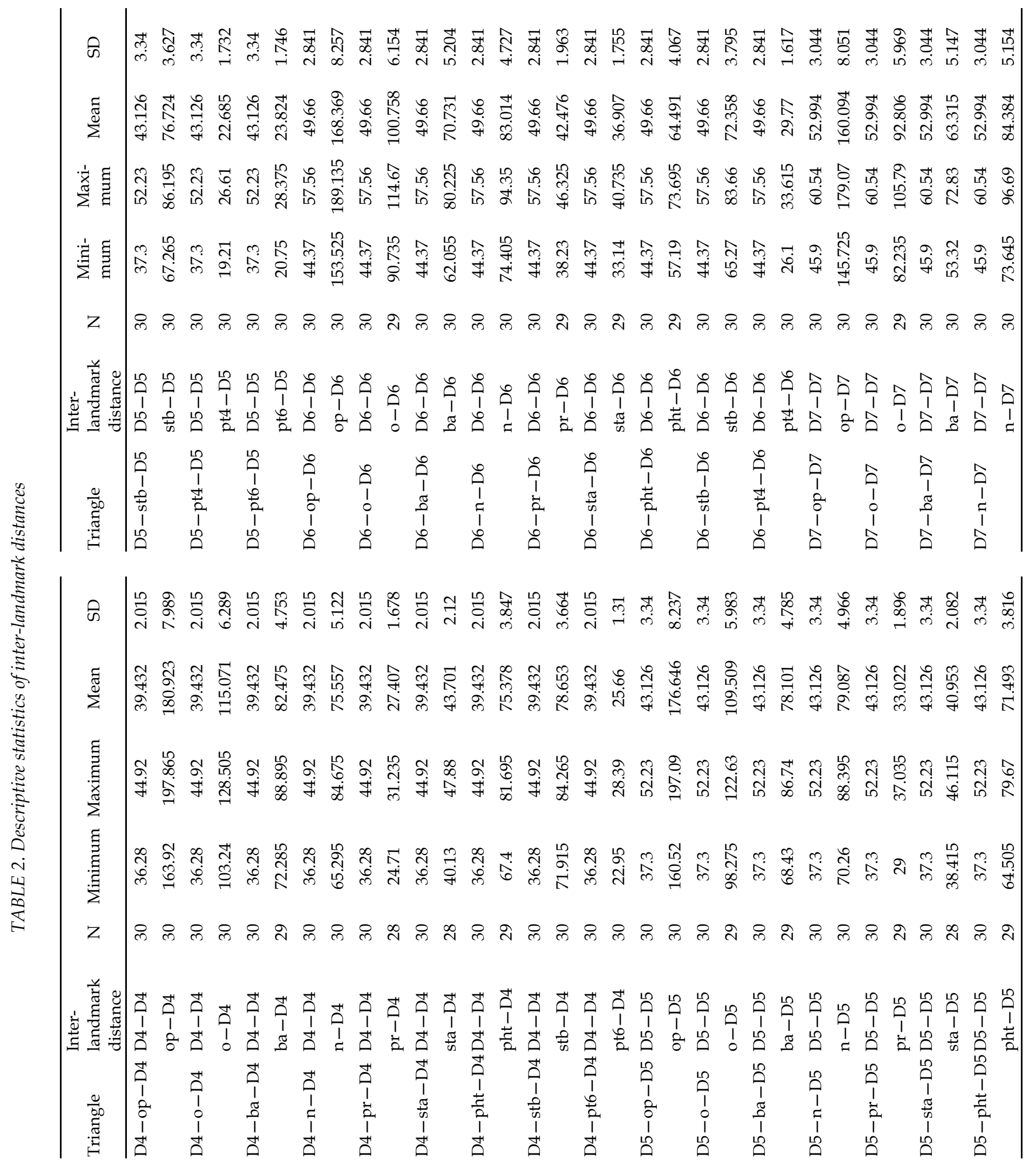




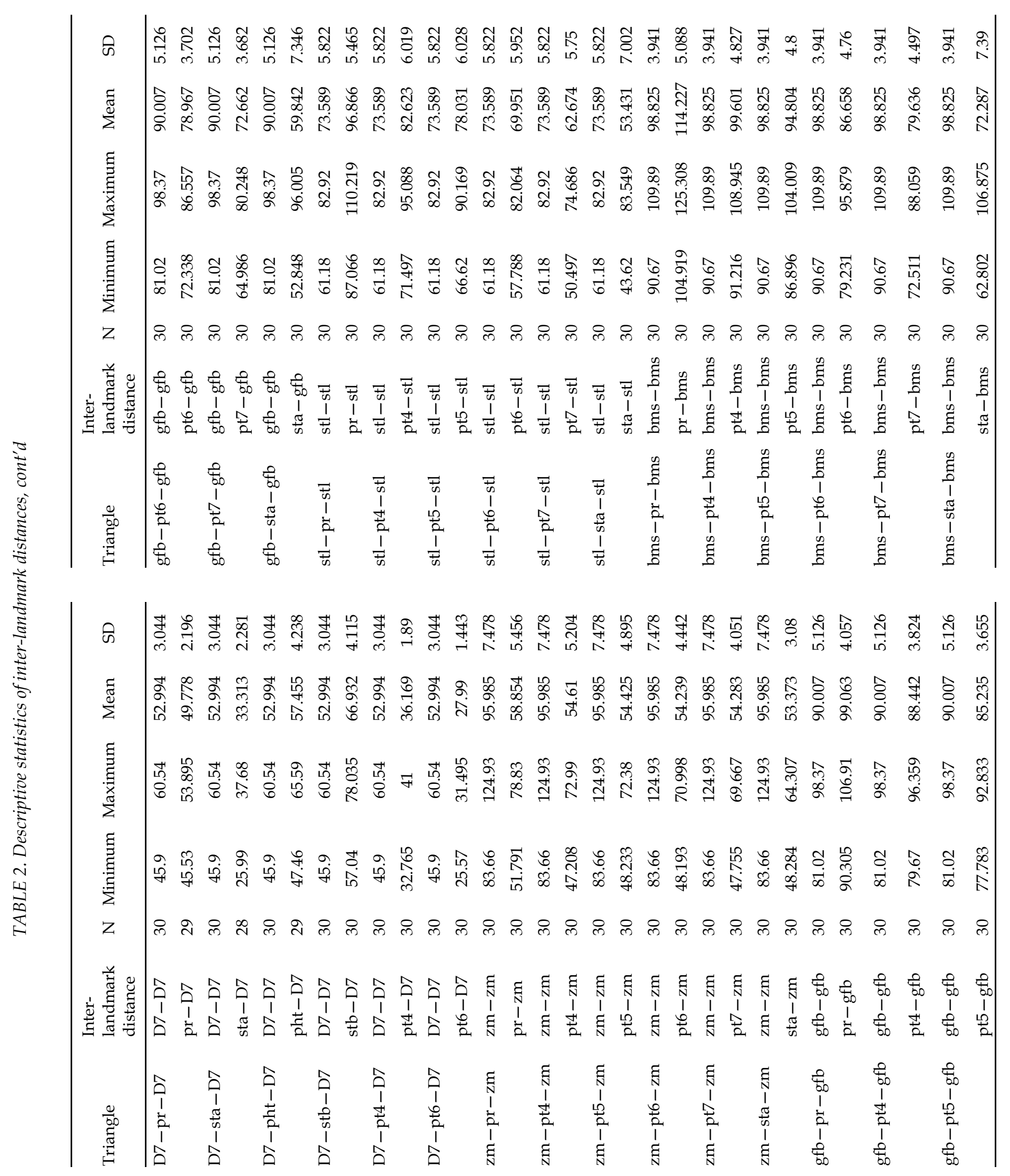


landmark distances. PC1 includes the bilateral dental landmarks and the midline landmarks of the base of the cranium. The loadings of the distances that include the $o, b a$, pht midline landmarks with all of the dental bilateral landmarks (D4, D5, D6 and D7) are slightly higher than the others. Also, the distances that include the $p r, p t 4, p t 5, p t 6, p t 7$ and sta maxillary midline landmarks with the $g f b$ and $b m s$ bilateral landmarks show high shared variance for PC1. Thus, PC1 is interpreted as representing the "cranial base system', as all of these inter-landmark distances load in a positive direction, with similar eigenvector coefficients.

Component two (PC2) accounts for $13.05 \%$ of the sample variance, and exclusively contrasts the landmarks of the oral cavity (the 'oral cavity system'), with lower shared variance for the other landmarks of the base and upper cranium.

Component three (PC3) is attributable to the vertical dimension (the 'upper cranium system'), and consists of compensatory relationships among high positive loadings that include the $z m$ bilateral landmark and the midline maxillary landmarks ( $p r, p t 4, p t 5, p t 6$, $p t 7$, sta) and high negative loadings that include the stl bilateral landmark and the same midline maxillary landmarks. Thus, individuals with large transversal distances (i.e., bizygomatic breadth) are predisposed to lower distances that include the $s t l$ bilateral landmark. The PC3 component explains 11.13\% of the variation.

The bivariate Pearson product-moment correlations between the selected inter-landmark distances derived from the first three PCs are given in Tables 4 to 6. For PC1, all of the selected pairwise correlations are positive and are highly correlated between themselves. For PC2, the selected bivariate correlations are also positive, and generally with high-intermediate values. Finally, for the correlations of PC3, the distances that include the $z m$ landmark are positively highly correlated between themselves. The distances that include the $s t l$ landmark are also positively correlated between themselves, although with lower values than for the $z m$ landmark. However, both of these groups of inter-landmark distances are generally not correlated between each other, with negative values that are close to zero.

\section{DISCUSSION}

New dental and cranial landmarks and craniometric measurements related to one another have been proposed. They may have interesting applications in physical anthropology and in other research areas such as craniofacial clinic and surgery.

In the principal component analysis, PC1 shows correlations between the cranial base and the maxil- lary distances. The landmarks of the cranial base system refer to muscle insertions, articular joints, and vascular and neuronal areas. Basion, which is the midpoint on the anterior margin of the foramen magnum on the occipital bone, provides insertion for the apical occipital odontoid ligament. The medulla oblongata continues into the spinal cord through the foramen magnum, which also provides a passage to accessory nerves and the vertebral arteries, the posterior and anterior spinal arteries, the tectorial membrane of the atlanto-axial joint, and the alar ligaments that connect the sides of the odontoid process on the axis to tubercles on the medial side of the occipital condyle. Approximately $1 \mathrm{~cm}$ from basion, there is the pharyngeal tubercle, on which there are the occipitopharyngeal ligament, the constrictor pharyngis superior muscle, and the anterior longitudinal ligament. The glenoid fossa of the temporal bone receives the mandibular condyles, and it is an important component of the temporomandibular joint. The mastoid process is a point of attachment for several muscles: the splenius capitis, longissimus capitis, digastric posterior belly, and sternocleidomastoid occipital condyle (Testut, 1943; Latarjet and Ruiz Liard, 2008).

All of the midline and lateral landmarks that are distributed in the cranial base system appear to be the nodes of a network that includes both the anterior and posterior legs of the skull base (Andria et al., 2004). The cranium has a complex architecture that is characterized by 'frames and trusses' that can withstand various mechanical stresses. At the same time, the skull is an efficient engineering solution to numerous functional requirements (which are often in conflict which each other), and the result of biological compromises; e.g., it protects the brain and the organs of sense that it contains, including the airways and the entrance to the digestive tract (Dubrul, 1988). The masticatory system is deeply integrated into this cranial architecture. In this context, the statistical correlations between the inter-landmark distances can be interpreted from a biodynamic and functional point of view.

The growth of the cranial base, the position and size of the cervical system (i.e., vertebral column), and the hyoid bone all have an influence on the morphogenesis and growth of the maxillofacial complex (Bedoya et al., 2014; Arntsen and Sonnesen, 2011). This integrated functional and anatomical system is well known, and it has important applications in dentistry, not only at the macroscopic level (Andria et al., 2004), but also histologically. The bone cells behave like a network of neurons, and the vascular and neural channels appear to be part of a complex biological system (Bhangu et al., 2001). The correlations of the linear distances among these demonstrate their inter- 
TABLE 5. Bivariate product-moment correlations for inter-landmark distances included in PC2

\begin{tabular}{|c|c|c|c|c|c|c|c|c|c|c|c|c|c|c|}
\hline & D14-D24 & pr-D4 & pt6-D4 & D15-D25 & pr-D5 & pt4-D5 & pt6-D5 & D16-D26 & pr-D6 & pt4-D6 & D17-D27 & pr-D7 & pt4-D7 & pt6-D7 \\
\hline D14-D24 & - & & & & & & & & & & & & & \\
\hline pr-D4 & 0.613 & - & & & & & & & & & & & & \\
\hline pt6-D4 & 0.682 & 0.254 & - & & & & & & & & & & & \\
\hline D15-D25 & 0.723 & 0.454 & 0.699 & - & & & & & & & & & & \\
\hline pr-D5 & 0.684 & 0.761 & 0.617 & 0.705 & - & & & & & & & & & \\
\hline pt4-D5 & 0.666 & 0.366 & 0.758 & 0.966 & 0.651 & - & & & & & & & & \\
\hline pt6-D5 & 0.678 & 0.431 & 0.699 & 0.985 & 0.690 & 0.945 & - & & & & & & & \\
\hline D16-D26 & 0.718 & 0.397 & 0.629 & 0.939 & 0.621 & 0.893 & 0.914 & - & & & & & & \\
\hline pr-D6 & 0.686 & 0.735 & 0.637 & 0.665 & 0.958 & 0.592 & 0.682 & 0.624 & - & & & & & \\
\hline pt4-D6 & 0.591 & 0.232 & 0.870 & 0.878 & 0.607 & 0.907 & 0.878 & 0.876 & 0.622 & - & & & & \\
\hline D17-D27 & 0.484 & 0.282 & 0.544 & 0.725 & 0.463 & 0.757 & 0.705 & 0.764 & 0.452 & 0.733 & - & & & \\
\hline pr-D7 & 0.645 & 0.654 & 0.587 & 0.621 & 0.840 & 0.560 & 0.639 & 0.612 & 0.904 & 0.592 & 0.588 & - & & \\
\hline pt4-D7 & 0.427 & 0.179 & 0.766 & 0.726 & 0.496 & 0.762 & 0.747 & 0.721 & 0.528 & 0.876 & 0.830 & 0.672 & - & \\
\hline pt6-D7 & 0.473 & 0.237 & 0.543 & 0.726 & 0.422 & 0.745 & 0.723 & 0.768 & 0.433 & 0.738 & 0.972 & 0.619 & 0.882 & - \\
\hline
\end{tabular}

Significant correlations $(p<0.05)$ are in bold.

TABLE 6. Bivariate product-moment correlations for inter-landmark distances included in PC3

\begin{tabular}{|c|c|c|c|c|c|c|c|c|c|c|c|c|c|c|}
\hline & $\mathrm{zm}-\mathrm{zm}$ & pr-zm & pt4-zm & pt5-zm & pt6-zm & $\mathrm{pt} 7-\mathrm{zm}$ & sta-zm & stl-stl & pr-stl & pt4-stl & pt5-stl & pt6-stl & pt7-stl & sta-stl \\
\hline zm-zm & - & & & & & & & & & & & & & \\
\hline pr-zm & 0.955 & - & & & & & & & & & & & & \\
\hline pt4-zm & 0.946 & 0.966 & - & & & & & & & & & & & \\
\hline pt5-zm & 0.944 & 0.953 & 0.975 & - & & & & & & & & & & \\
\hline pt6-zm & 0.966 & 0.947 & 0.964 & 0.987 & - & & & & & & & & & \\
\hline $\mathrm{pt7}$-zm & 0.965 & 0.921 & 0.935 & 0.950 & 0.980 & - & & & & & & & & \\
\hline sta-zm & 0.908 & 0.816 & 0.801 & 0.821 & 0.878 & 0.923 & - & & & & & & & \\
\hline stl-stl & -0.275 & -0.322 & -0.213 & -0.257 & -0.300 & -0.284 & -0.249 & - & & & & & & \\
\hline pr-stl & -0.187 & -0.263 & -0.222 & -0.236 & -0.207 & -0.120 & 0.051 & 0.556 & - & & & & & \\
\hline pt4-stl & -0.220 & -0.322 & -0.229 & -0.233 & -0.225 & -0.167 & -0.036 & 0.645 & 0.943 & - & & & & \\
\hline pt5-stl & -0.255 & -0.354 & -0.272 & -0.263 & -0.255 & -0.204 & -0.070 & 0.648 & 0.935 & 0.988 & - & & & \\
\hline pt6-stl & -0.245 & -0.356 & -0.284 & -0.278 & -0.257 & -0.201 & -0.053 & 0.632 & 0.926 & 0.973 & 0.988 & - & & \\
\hline pt7-stl & -0.279 & -0.389 & -0.319 & -0.321 & -0.299 & -0.241 & -0.088 & 0.666 & 0.918 & 0.964 & 0.973 & 0.990 & - & \\
\hline sta-stl & -0.180 & -0.210 & -0.207 & -0.169 & -0.170 & -0.159 & -0.092 & 0.061 & 0.400 & 0.406 & 0.486 & 0.460 & 0.385 & - \\
\hline
\end{tabular}

Significant correlations $(p<0.05)$ are in bold. 
dependence and might reflect the complex and combined ontogenetic development of this anatomical region (Gazi-Coklica et al., 1997; Ranly, 2000). Moreover, the cranial base and its component parts appear to have influences on the alveolar and dental positions in the maxillary bone (Andria et al., 2004; Arntsen and Sonnesen, 2011).

Healthy development of the cranial base might be in compliance with the proportions and balance between the parties concerned; i.e., the correlations between malocclusion and anthropometric measures outside the normal range of variability appear to confirm this assumption (Simoes, 2010). PC1 (i.e., the 'cranial base system') suggests that the development and mechanical actions of the masticatory and suprahyoid muscles can influence the morphology of the maxillary dental arch, although they do not insert into the alveolar bone (Xuguang, 2005; Deshayes, 2006).

PC2 depicts the oral cavity as a wellcircumscribed system (i.e., the 'oral cavity system'), where the distances between the landmarks are related to each other. The correlations between the maxillary anterior teeth and the facial landmarks have been described in the literature, whereby the intercanine tip width and the width of the distal surface of the canine have a relationship with the intercommissural width and the distance between left and right projection lines drawn from the inner canthus of the eyes to the alae of the nose (Kini and Angadi, 2013; Sinavarat et al., 2013). Proportional relationships between the bizygomatic width and the width of the maxillary central incisor, the intercanine distance, and the interalar width have also been observed in women (Hasanreisoglu et al., 2005). Furthermore, in an indirect way, clinical trials have suggested that there is interdependence between the morphology and the size of the palate and the maxillary dental arch (Toro-Ibacache et al., 2014; Liu et al., 2011).

In any case, previous studies have not considered the palatal landmarks and did not evaluate the possible relationships among the palatine and maxillary dental inter-landmark distances. These data in the present study show correlations among the dental and palatal inter-landmark measures, and the close anatomical and functional connections between the maxillary teeth and the palate.

PC 3 shows a relationship between the measures delimited by the bilateral landmarks (i.e., $z m, s t l$ ) and the midline maxillary landmarks (i.e., $p r, p t 4$, $p t 5, p t 6, p t 7, s t a)$. We have defined the PC 3 component as the 'vertical dimension system' because it includes the $z m$ landmark in the splanchnocranium, which is is the most prominent point of the zygo- matic bone, and which participates in the formation of the temporal and infratemporal fossae, and also forms part of the lateral wall and floor of the orbital cavity.

The cranial base consists of two legs (Andria et al., 2004). For cephalometric measurement purposes, the maxilla is attached to the anterior leg, which extends from the sella turcica (s) to the frontal-nasal suture $(n)$. The mandible is attached to the posterior leg, and extends from the sella turcica (s) to the anterior border of the foramen magnum, which is defined as the basion (ba). Andria et al. (2004) demonstrated that the angular $b a-s / \mathrm{FH}$ (FH, Frankfurt Horizontal plane), the linear $b a-s$ (in $\mathrm{mm}$ ), and the proportional length of $b a-s / b a-n$ are all statistically negatively correlated to the facial angle. They thus concluded that the posterior cranial base leg is the controlling factor in relating the cranial base to mandibular prognathism. Our data are similar in some ways, and complete their study by suggesting that the posterior leg of the cranial base can affect the maxilla relationship to the other facial structures.

The three components, PC1, PC2 and PC3, which refer to the 'cranial base', the 'oral cavity' and 'upper cranium' systems, respectively, include linear measurements that are statistically correlated to each other. In other words, even if the three components are independent, a large number of landmarks that were used in the anthropometric analysis of the skulls are recurrent in each of these three components; e.g. $p r, p t 4, p t 5, p t 6, p t 7$ have important roles in describing the anthropometric characteristics of all three of these systems, and they are correlated with the other lateral and midline landmarks that are distributed in the PC1, PC2 and PC3 components.

For each of these three systems described by the PC1, PC2 and PC3 components, it is possible to draw various correlated linear distances that demonstrate that there are connections between the different anatomical regions. We analyzed the skulls of adult individuals, although our data suggest that the normal ontogenetic development of the cranium (and its legs) takes place according to anthropometric measures and proportions, which need to be further investigated. Moreover, the clinical data show the conservation of reports of the balanced relationship among the anatomical structures of the complex cranial, maxillary and mandibular anatomical regions during development, which are essential for growth harmonics (Mcnamara and Brudon, 1993).

The correlations between the lateral (dental and facial) and midline ( $p r, p t z, p t g, s t a, p h t, b a)$ landmarks of the skull appear to be within the more general context of the symmetry that characterizes the 
entire human body (Weyl, 1952; Gardner, 1990). In terms of their application in the near future, the correlations shown in this study suggest that we can calculate the position of a landmark starting from known anthropometric distances; e.g., the correlation between dental landmarks and landmarks placed on the midline near the foramen magnum ( $p h t, b a, o$ ) can provide new and very interesting information on the relationships between dental occlusion disturbances and the curvature of the vertebral spine (RamirezYanez et al., 2014; Shimazaki et al., 2003).

Moreover, the results could contribute to comprehension of the phenomenon described by Gould as allometry (Gould, 1966), who suggested that variation in the absolute size of the total organism or specific parts can generate proportional changes in the dimensions of particular anatomical traits, as well as correlated physiological and behavioral changes.

\section{CONCLUSIONS}

We propose new dental (D4, D5, D6, D7, pt4, pt5, $p t 6, p t 7)$ and craniometric (pht, gfb, stl, bms) landmarks that may have important application in physical anthropology and clinical dentistry.

Our data show correlations among anthropometric linear measurements that are distributed in different anatomical regions of the skull. We have defined these as the cranial base, the oral cavity, and the upper cranium systems. They open questions into the existence of mathematical laws useful to calculate the position of a landmark starting from known anthropometric distances. The same laws could describe normal/healthy ontogenetic development of the entire cranium. To verify this hypothesis, the next stages of this research will be to increase the sample size and to include skulls of individuals of different sex, developmental age and ethnic groups.

\section{LITERATURE CITED}

Andria LM, Leite LP, Prevatte, TM, King LB. 2004. Correlation of the cranial base angle and its components with other dental/skeletal variables and treatment time. Angle Orthod 74:361-366.

Arntsen T, Sonnesen L. 2011. Cervical vertebral column morphology related to craniofacial morphology and head posture in preorthodontic children with Class II malocclusion and horizontal maxillary overjet. Am J Orthod Dentofacial Orthop 140:e1-e7.

Bhangu PS, Genever PG, Spencer GJ, Skerry TM. 2001. Evidence for targeret vesicular glutamate exocytosis in osteoblasts. Bone 29:16-23.

Bedoya A, Landa Nieto Z, Zuluaga LL, Rocabado M. 2014. Morphometry of the cranial base and the cranial-cervical-mandibular system in young pa- tients with type II, division 1 malocclusion, using tomographic cone beam. Cranio 32:199-207.

Capasso L. 2015. Trattato di Antropologia. Roma: Società Editrice Universo.

Deshayes MJ. 2006. Les déformations crâniennes asymétriques et leur retentissement dento-facial et occlusal. Orthod Fr 77:87-99.

Dubrul LE. 1988. Anatomia orale. Milano: Edi Ermes.

Gapert R, Black S, Last J. 2013. Test of age-related variation in the craniometry of the adult human foramen magnum region: implications for sex determination methods. Forensic Sci Med Pathol 9:478-488.

Gardner M. 1990. The ambidextrous universe: symmetry and asymmetry from mirror reflections to superstrings. New York: W.H. Freeman.

Gazi-Coklica V, Muretić Z, Brcić R, Kern J, Milicić A. 1997. Craniofacial parameters during growth from the deciduous to permanent dentition - a longitudinal study. Eur J Orthod 19(6):681-689.

Gonzalez RA. 2012. Determination of sex from juvenile crania by means of discriminant function analysis. Forensic Sci 57:24-34.

Gould SJ. 1966. Allometry and size in ontogeny and phylogeny. Biol Rev 41:587-640.

Hanihara T, Ishida H, Dodo Y. 2003. Characterization of biological diversity through analysis of discrete cranial traits. Am J Phys Anthropol 121:241-251.

Hasanreisoglu U, Berksun S, Aras K, Arslan I. 2005. An analysis of maxillary anterior teeth: facial and dental proportions. J Prosthet Dent 94:530-538.

Irurita J, Alemán I, Viciano J, De Luca S, Botella MC. 2014. Evaluation of the maximum length of deciduous teeth for estimation of the age of infants and young children: proposal of new regression formulas. Int J Legal Med 128:345-352.

Kimbel WH, Rak Y. 2010. The cranial base of Australopithecus afarensis: new insights from the female skull. Philos Trans R Soc Lond B Biol Sci 365:33653376.

Kini AY, Angadi GS. 2013. Biometric ratio in estimating widths of maxillary anterior teeth derived after correlating anthropometric measurements with dental measurements. Gerodontology 30:105 $-111$.

Latarjet M, Ruiz Liard A. 2008. Anatomia Humana, vol. 1, 4th edition. Buenos Aires: Panamericana.

Liu R, Lu D, Wamalwa P, Li C, Hu H, Zou S. 2011. Craniofacial morphology characteristics of operated unilateral complete cleft lip and palate patients in mixed dentition. Oral Surg Oral Med Oral Pathol Oral Radiol Endod 112:e16-e25.

Martin R, Saller K. 1957-1966. Lehrbuch der Anthropologie. Stuttgart: Fischer Verlag. 
Mcnamara JAJr, Brudon EWL. 1993. Orthodontic and orthopedic treatment in the mixed dentition. Ann Arbor: Needham Press.

Moyers RE, van der Linden FPGM, Riolo ML, McNamara JAJr. 1976. Standards of Human Occlusal Development, monograph 5, Craniofacial Growth Series. Ann Arbor: University of Michigan.

Ngeow WC, Aljunid ST. 2009. Craniofacial anthropometric norms of Malays. Singapore Med J 50:525-528.

Parenti R. 1955. Biologia delle razze umane. Pisa: Libr. Goliardica.

Perez SI, Bernal V, Gonzalez PN. 2007. Evolutionary relationships among prehistoric human populations: an evaluation of relatedness patterns based on facial morphometric data using molecular data. Hum Biol 79:25-50.

Ranly DM. 2000. Craniofacial growth. Dent Clin North Am 44(3):457-470.

Ramirez-Yanez GO, Mehta L, Mehta NR. 2014. The effect of dental occlusal disturbances on the curvature of the vertebral spine in rats. Cranio DOI: $10.1179 / 2151090314$ Y.0000000017.

Relethford JH. 2002. Apportionment of global human genetic diversity based on craniometrics and skin color. Am J Phys Anthropol 118:393-398.

Sarigu M, Floris GU, Floris R, Pusceddu V. 2016. The Osteological Collection of the University of Cagliari: From Early Neolithic to Modern Age. HOMO J. Comp. Hum. Biol. http:// dx.doi.org/10.1016/j.jchb.2016.03.001.

Shimazaki T, Motoyoshi M, Hosoi K, Namura S. 2003. The effect of occlusal alteration and masticatory imbalance on the cervical spine. Eur J Orthod 25:457-463.

Simoes WA. 2010. Ortopedia funzionale dei mascellari. Livorno: NIKE Edizioni.

Sinavarat P, Anunmana C, Hossain S. 2013. The relationship of maxillary canines to the facial anatomical landmarks in a group of Thai people. J Adv Prosthodont 5:369-373.

Spencer F. 1997. History of Physical Anthropology. New York: Garland Pub.

Testut L. 1943. Anatomia umana. Torino: Unione Tipografico-Editrice Torinese.

Toro-Ibacache V, Cortés Araya J, Díaz Muñoz A, Manríquez Soto G. 2014. Morphologic variability of nonsyndromic operated patients affected by cleft lip and palate: a geometric morphometric study. Am J Orthod Dentofacial Orthop 146:346354.

Xuguang N. 2005. Cranial base in craniofacial development: developmental features, influence on facial growth, anomaly, and molecular basis. Ac- ta Odontol Scand 63:127-135.

Veroni A, Nikitovic D, Schillaci MA. 2010. Brief communication: sexual dimorphism of the juvenile basicranium. Am J Phys Anthropol 141:147-151.

Viciano J, D'Anastasio R, Capasso L. 2015. Odontometric sex estimation on three populations of the Iron Age from Abruzzo region (centralsouthern Italy). Arch Oral Biol 60:100-115.

Weyl H. 1952. Symmetry. Princeton: Princeton University Press. 